\title{
Coronary angioplasty and left ventricular function in single vessel coronary artery disease
}

\author{
Y C NAJM, A D TIMMIS, M N MAISEY, L MANUEL Y PINIES, * A SALINAS, * \\ P V L CURRY, EDGAR SOWTON \\ From the Departments of Cardiology and Nuclear Medicine, Guy's Hospital, London
}

SUMMARY Left ventricular function was investigated in 86 patients with single vessel coronary? artery disease before and three to six months after successful angioplasty. Before angioplasty. thallium-201 perfusion scintigraphy and technetium-99m gated equilibrium ventriculography in $\tilde{i}_{i}$ most patients showed that stress testing (exercise and ice water stimulation and isometric handgrip respectively) induced myocardial perfusion defects that were associated with a mean (SD) drop in? left ventricular ejection fraction from $64(6) \%$ to $56(7) \%$. After angioplasty there was residualcoronary stenosis of $\leqslant 20 \%$ of the diameter of the vessel in 78 patients (group 1) and of between 203 and $50 \%$ in eight patients (group 2). After the procedure the perfusion defects seen during stresso resolved in $86 \%$ of group 1 and in $87 \%$ of group 2 . Despite the apparent improvement in myocardial perfusion left ventricular dysfunction persisted in group 2-that is during stress the leftio ventricular ejection fraction fell from $65 \%(6)$ to $56 \%$ (5). In group 1 , on the other hand, the improvement in myocardial perfusion was associated with significant improvement in lefto ventricular function with a normal increase in ejection fraction from 63 (5) at rest to 67 (6) during stress. Radionuclide studies, one to six weeks after angioplasty in 30 group 1 patients showed continuing left ventricular decompensation during stress in nine $(30 \%)$ of them despite correction of perfusion defects. But reinvestigation three to six months after the procedure showed recovery of left ventricular function with an increase in ejection fraction from 66 (5) at rest to 69 (7) durings stress.

These data indicate that coronary angioplasty procedures that give a residual stenosis of $\leqslant 20 \%$ improve myocardial perfusion and the response of the left ventricle to stress. The functiona审 improvement may be delayed for up to three months, however, possibly because arterial healing at the angioplasty site is delayed. On the other hand, when the residual stenosis is between 21 ands $50 \%$ of the diameter of the vessel subclinical left ventricular dysfunction during stress may persise indefinitely.

Percutaneous transluminal coronary angioplasty effectively dilates diseased coronary arteries and in most cases leads to symptomatic relief and improved myocardial perfusion as judged by thallium-201 scintigraphy. ${ }^{1}$ The effects of coronary angioplasty on left ventricular contractile function, however, are variable and although some improvement in the

Requests for reprints to Dr Y C Najm, Department of Cardiology, Guy's Hospital, St Thomas Street, London SE1 9RT.

*Present address: Departamento de Patologia General, Universidad del Pais Vasco, Bilbao, Spain.

Accepted for publication 24 October 1988 response of ejection fraction to exercise can often be shown, in many patients a dyskinetic left ventricular contraction pattern persists after a successful procedure. ${ }^{12}$ The cause is unknown but continuing of subclinical myocardial ischaemia is the most plausi- $N$ ble explanation. To investigate further the effects of $\mathrm{N}$ successful coronary angioplasty on left ventricular 0 perfusion and contractile function, we performed radionuclide studies on 86 patients before angio- $\frac{C}{8}$ plasty, soon after angioplasty, and between three and $\stackrel{\oplus}{\rightarrow}$ six months afterwards. This provided new informa- 0 tion on the evolution of myocardial recovery after a successful procedure. We paid particular attention to $\mathbb{\Omega}$ the effect of residual stenosis on left ventricular $\stackrel{\mathbb{D}}{\mathbb{D}}$ performance. 


\section{Patients and methods}

\section{PATIENTS}

Of 95 patients originally considered for inclusion in the study, 86 underwent successful angioplasty; they form the basis of this report. There were 72 men and 14 women aged 29 to 66 years (mean (SD) 53 (9)). All had stable symptomatic single vessel coronary artery disease of the left anterior descending $(n=49)$, circumflex $(n=18)$, or right coronary arteries $(n=19)$. Resting left ventricular function was normal or near normal in every case although in 21 of the 29 patients with a history of previous myocardial infarction left ventriculography showed limited regional hypokinesis. Patients with akinetic myocardial segments, cardiomyopathy, or valvar heart disease were excluded. We also excluded patients with musculoskeletal disorders, intermittent claudication, and other non-cardiac disorders that prevented adequate exercise.

\section{Coronary angioplasty}

Angioplasty was carried out as previously described by Sowton $e t ~ a l .{ }^{3}$ Criteria for a successful procedure included a residual coronary stenosis of $\leqslant 50 \%$ the transluminal diameter and completion of the procedure without serious complications (myocardial infarction, referral for urgent bypass surgery, death). A 12 lead electrocardiogram was obtained before angioplasty, again immediately afterwards, and daily thereafter for three days. Electrocardiographic data together with daily measurements of plasma concentrations of creatine kinase excluded myocardial infarction in every patient. Before angioplasty patients were treated with nitrates, $\beta$ blockers, and calcium antagonists. After the procedure $\beta$ blockers were stopped (except in 19 hypertensive patients). Treatment with isosorbide mononitrate $20 \mathrm{mg}$ twice daily, nifedipine slow release $20 \mathrm{mg}$ twice daily, and aspirin $300 \mathrm{mg}$ daily was continued. The luminal diameter of the coronary artery (in identical radiographic projections before and after coronary angioplasty) was measured by precision callipers. The degree of stenosis was expressed as a percentage of the diameter of the immediately adjacent normal artery.

\section{NON-INVASIVE IMAGING}

In every patient thallium-201 myocardial perfusion scintigraphy during exercise and technetium-99m gated equilibrium ventriculography were performed before angioplasty (within four weeks of the procedure) and again three to six months afterwards. In 30 patients (all with a residual stenosis of $\leqslant 20 \%$ radionuclide imaging was performed early $(<6$ weeks) after coronary angioplasty so that the recovery of the left ventricle could be examined. In each patient studies of myocardial perfusion and ventriculography were carried out on the same day. Imaging was performed at least three hours after eating. In all patients, except those who were hypertensive, $\beta$ blockers were stopped for 46-72 hours before the radionuclide studies; all other medication was continued. The images were interpreted by three independent observers.

Before thallium-201 tomography patients were exercised in the erect position on a bicycle ergometer at workloads that increased $25 \mathrm{~W}$ every two minutes. The exercise tests were maximal and symptom limited. Endpoints were: horizontal or downsloping ST segment depression $\geqslant 3 \mathrm{~mm}$, angina of increasing severity, a drop in systolic blood pressure $\geqslant 20 \mathrm{~mm} \mathrm{Hg}$ with progressive exercise, or significant rhythm disturbances. At peak exercise $60-80 \mathrm{MBq}$ of thallium-201 was injected via an antecubital vein and the patient continued to exercise for a further minute at a lower workload. Myocardial imaging was started five minutes after the isotope injection and was repeated after three hours to assess redistribution. The patients lay supine beneath a gamma camera with a large field of view and a seven-pinhole collimator. Images were recorded in a $128 \times 128$ matrix and reconstructed in the long axis of the heart in seven slices. We analysed four tomographic slices from apex to base of the left ventricle. Semiquantitative curves showing regional uptake for each patient in $10^{\circ}$ segments were displayed in polar coordinates that were normalised to the area of maximum activity. Washout curves were constructed by plotting the absolute counts for exercise images and delayed images. These quantitative data were used to assist interpretation of the image.

Technetium-99m gated equilibrium ventriculography with in vitro labelling of red blood cells ( ${ }^{99 m} \mathrm{Tc}, 500-800 \mathrm{MBq}$ ) was performed after the completion of the thallium-201 study. Images were recorded for 10 minutes in the anterior view and in the modified (caudal tilt) left anterior oblique $45^{\circ}$ view that gave the best image of the left ventricular septum. A general purpose parallel hole collimator was used with a gamma camera with a small field of view. Stress was applied as ice water stimulation for five minutes followed by isometric handgrip for five minutes during which images were recorded in the modified left anterior oblique $45^{\circ}$ position. Cardiac gating was triggered by the $R$ wave of the electrocardiogram and the information was stored in 18 frames throughout the cardiac cycle, in a $64 \times 64$ matrix. The 18 frames were displayed in cine mode for the evaluation of regional abnormalities of wall motion. The left ventricular ejection fraction in the modified left anterior oblique $45^{\circ}$ view was calculated by a 
Najim, Timmis, Maisey, Pinies, Salinas, Curry, Sowton $\underset{\frac{0}{T}}{\frac{\square}{\Phi}}$

semiautomated method for defining the left ventricular area of interest, with automatic selection of background. Regional abnormalities of wall motion were assessed visually.

STATISTICAL ANALYSES

Comparisons of proportions were by $\chi^{2}$ or Fisher's exact tests, as appropriate. Differences between groups were assessed by Student's $t$ test.

\section{Results}

The 86 patients underwent successful angioplasty with a mean (1 SD) reduction in coronary artery stenosis from $89(10)$ of the coronary artery diameter to 24 (9). The patients were divided into two groups for later analysis. Group 1 was 78 patients in whom the residual stenosis was $\leqslant 20 \%$ (average $13(7) \%$ ) and group 2 was eight patients in whom the residual stenosis was $21-50 \%$ (average $38(7) \%$ ). Table 1 shows the effects of coronary angioplasty on the severity of stenosis and gradient, exercise haemodynamic function and performance, and left ventricular wall motion and perfusion during exercise. Figure 1 shows the functional responses, both global and regional, of wall motion to stress after angioplasty.

GROUP 1 ( $\leqslant 20 \%$ RESIDUAL STENOSIS)

Coronary angioplasty produced complete symptomatic relief in $90 \%$ of group 1 , and this was
Table 1 Results of percutaneous transluminal coronary angioplasty (PTCA) in groups 1 and 2

\begin{tabular}{|c|c|c|c|c|}
\hline & \multicolumn{2}{|l|}{$\begin{array}{l}\text { Group } 1 \\
(n=78)\end{array}$} & \multicolumn{2}{|l|}{$\begin{array}{l}\text { Group } 2 \\
(n=8)\end{array}$} \\
\hline & $\begin{array}{l}\text { Before } \\
P T C A\end{array}$ & $\begin{array}{l}\text { After } \\
\text { PTCA }\end{array}$ & $\begin{array}{l}\text { Before } \\
\text { PTCA }\end{array}$ & $\begin{array}{l}\text { After } \\
P T C A\end{array}$ \\
\hline $\begin{array}{l}\text { Age (yr) } \\
\text { Dilatations (n) }\end{array}$ & $\begin{array}{r}54(9) \\
6(2)\end{array}$ & & $\begin{array}{r}52(8) \\
7(3)\end{array}$ & \\
\hline $\begin{array}{l}\text { Stenosis (\%) } \\
\text { Gradient (mm Hg) }\end{array}$ & $\begin{array}{c}86(10) \\
59(18) \\
545(254)\end{array}$ & $\begin{array}{c}13(7)^{\star \star \star} \\
9(8)^{\star \star \star} \\
698(285)^{\star \star \star}\end{array}$ & $\begin{array}{c}93(10) \\
58(23) \\
616(251)\end{array}$ & $\begin{array}{l}38(7)^{\star \star \star \star} \\
11(13)^{\star \star \star \star} \\
740(363)\end{array}$ \\
\hline $\begin{array}{l}\text { Total work } \\
\text { (W.min) }\end{array}$ & $545(254)$ & $698(285)^{\star \star \star}$ & $616(251)$ & $740(363)$ \\
\hline $\begin{array}{l}\text { Rest HR (beats/ } \\
\text { min) }\end{array}$ & $71(12)$ & $70(10)$ & $80(21)$ & $73(15)$ \\
\hline $\begin{array}{l}\text { Rest DP }\left(\times 10^{3}\right) \\
\text { Maximal HR } \\
\text { (beats } / \min \text { ) }\end{array}$ & $\begin{array}{c}9(2) \\
141(21)\end{array}$ & $\begin{array}{c}9(2) \\
155(21)^{\star \star \star}\end{array}$ & $\begin{array}{c}10(3) \\
147(19)\end{array}$ & $\begin{array}{c}9(2) \\
156(21)\end{array}$ \\
\hline$\underset{\left(\times 10^{3}\right)}{\text { Maximal DP }}$ & $23(5)$ & $27(6)^{\star \star \star}$ & $24(4)$ & $27(8)$ \\
\hline $\begin{array}{l}\text { Effort angina (n) } \\
\text { Ex peif defects (n) }\end{array}$ & $\begin{array}{l}78 \\
78\end{array}$ & $\begin{array}{l}8 \star \star \star \\
9 \star \star \star\end{array}$ & $\begin{array}{l}8 \\
8\end{array}$ & $\begin{array}{l}0^{\star \star \star} \\
2^{\star \star}\end{array}$ \\
\hline Rest RWA (n) & 19 & $5 \star \star$ & 3 & 2 \\
\hline Stress RWA (n) & 64 & 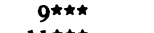 & 7 & 7 \\
\hline Stress $L V$ dilat (n) & 78 & $11^{\star \star \star}$ & 8 & 7 \\
\hline
\end{tabular}

${ }^{\star \star} p<0.01,{ }^{\star \star \star} p<0.001$ for difference compared with value before angioplasty. HR, heart rate; DP, double product; Ex perf, exercise perfusion; RWA, regional wall motion abnormality; LV dilat, global left ventricular dilatation.

reflected by an increase in peak workload during bicycle ergometry from 545 (254) to 698 (285) Watt.minutes $(p<0.001)$.

Before angioplasty thallium-201 scintigraphy during exercise showed fully or partially reversible perfusion defects in 73 patients and irreversible

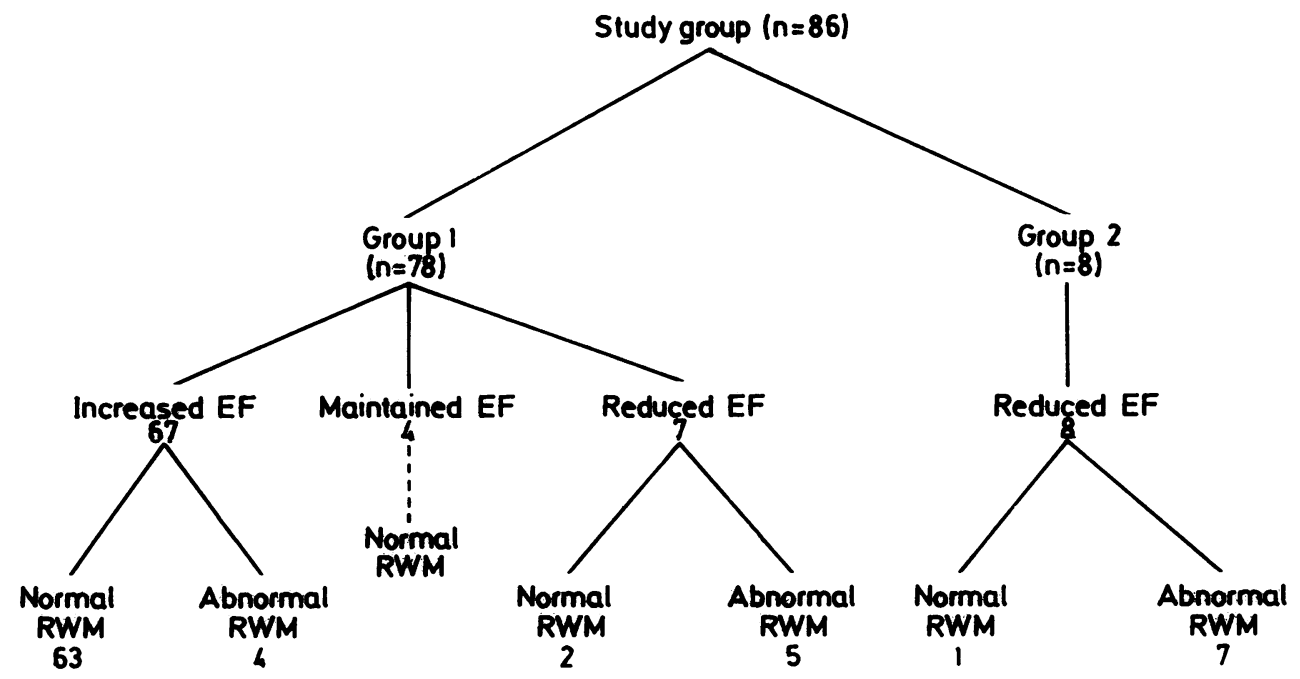

Fig 1 Effects of coronary angioplasty on the left ventricular response to exercise. Data for group 1 (residual stenosis $\leqslant 20 \%$ ) and group 2 (residual stenosis $>20 \%$ ) are shown. EF, left ventricular ejection fraction; $R W M$, regional wall motion. 

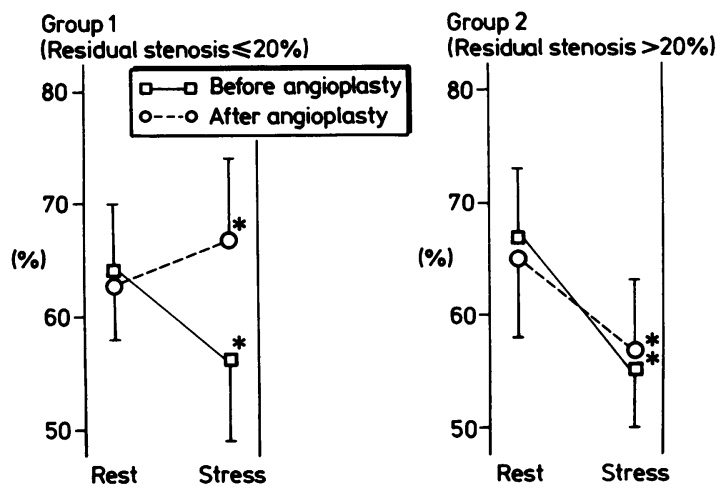

Fig 2 Effect of coronary angioplasty left ventricular ejection fraction during exercise and at rest in groups 1 and 2. ${ }^{\star} p<0.001$ compared with resting values.

defects in five patients. After angioplasty myocardial perfusion became normal in $69(88 \%)$ patients, but in the remaining nine patients perfusion abnormalities persisted in the territory of the dilated artery.
Radionuclide ventriculography before coronary angioplasty showed stress induced left ventricular decompensation in all patients, with a rise in systolic and diastolic cavity dimensions and reduction in ejection fraction from $64(6) \%$ at rest to $56(7) \%$ during stress ( $p<0.001$, fig 2). After coronary angioplasty there was an improvement in the response of the left ventricle. Improvement was delayed, however, in nine out of $\mathbf{3 0}$ patients (subgroup 1b) who were studied within six weeks of angioplasty (fig 3). Despite successful coronary angioplasty these nine patients showed persistent stress induced increases in the dimensions of the left ventricular cavity (table 2 ) associated with reductions in ejection fraction from $61(9) \%$ at rest to $52(9) \%$ $(p<0.05)$ at peak exercise. Nevertheless, when these nine patients were restudied three to six months after the angioplasty a delayed recovery of left ventricular function was shown by increases in ejection fraction from $66(5)$ to $69(7) \%(p<0.01)$ at peak exercise (fig 4). Thus six months after coronary angioplasty group 1 showed an overall improvement

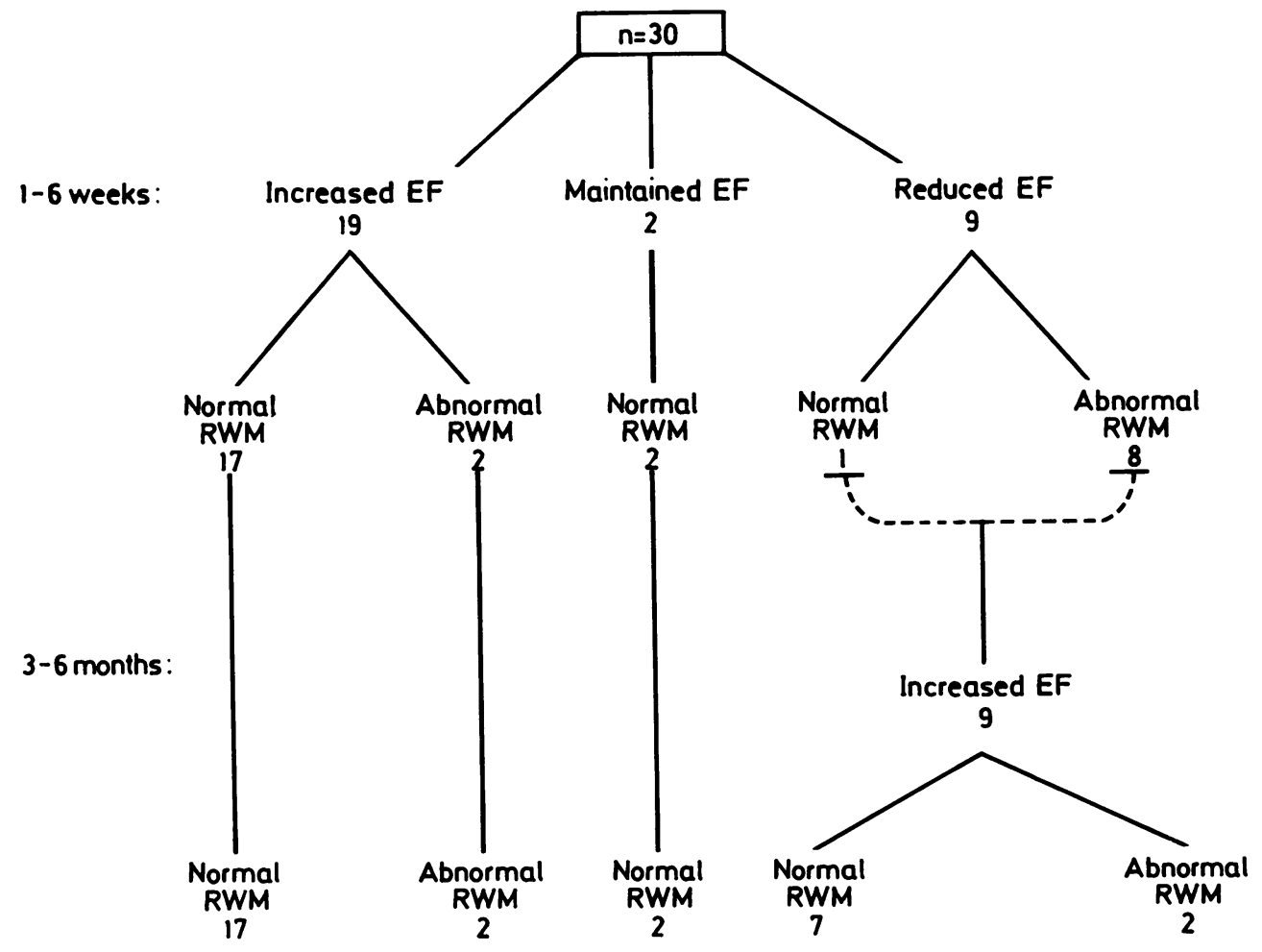

Fig 3 Results of early (1-6 weeks) and late (3-6 months) radionuclide ventriculography after successful coronary angioplasty in 30 patients all of whom had a residual stenosis $\leqslant 20 \%$ (group 1 ). Note that in nine cases (subgroup $1 b$ ) recovery of left ventricular function was delayed. EF, ejection fraction; $R W M$, regional wall motion. 
Table 2 Results of percutaneous transluminal coronary angioplasty (PTCA) in nine patients with $\leqslant 20 \%$ residual stenosis and delayed left ventricular recovery

\begin{tabular}{lccc}
\hline & $\begin{array}{l}\text { Before } \\
P T C A\end{array}$ & $\begin{array}{l}1-6 \text { weeks } \\
\text { after } \\
P T C A\end{array}$ & $\begin{array}{l}\text { 3-6 months } \\
\text { after } \\
P T C A\end{array}$ \\
\hline Age (yr) & $55(6)$ & & \\
Dilatations (n) & $5(1)$ & & \\
Stenosis (\%) & $83(9)$ & $10(7)^{\star \star \star}$ & \\
Gradient (mm Hg) & $67(19)$ & $8(8)^{\star \star \star}$ & \\
Total work (W.min) & $492(141)$ & $600(136)^{\star}$ & $631(129)^{\star \star}$ \\
Rest HR (beats/min) & $75(16)$ & $74(11)$ & $74(16)$ \\
Rest DP ( $\left.\times 10^{3}\right)$ & $9(2)$ & $9(2)$ & $9(2)$ \\
Maximal HR (beats/min) & $145(22)$ & $155(17)^{\star}$ & $158(16)^{\star}$ \\
Maximal DP ( $\left.\times 10^{3}\right)$ & $25(7)$ & $27(4)$ & $28(4)$ \\
Effort angina (n) & 9 & $0 \star \star \star$ & $0 \star \star \star$ \\
Ex perf defects (n) & 9 & $1 \star \star \star$ & $1 \star \star \star$ \\
Rest RWA (n) & 2 & 2 & 1 \\
Stress RWA (n) & 9 & 7 & $0 \star 0^{\star \star \star}$ \\
Stress LV dilat (n) & 9 & 9 & $1 \star \star \star$ \\
\hline
\end{tabular}

${ }^{\star} p<0.05,{ }^{\star \star} p<0.01,{ }^{\star \star \star} p<0.001$ for difference compared with value before angioplasty. $H R$, heart rate; $D P$, double product; Ex perf, exercise perfusion; RWA, regional wall motion abnormality; LV dilat, global left ventricular dilatation.

in left ventricular function. Only seven of the patients $(9 \%)$ showed persistent stress induced reductions in left ventricular ejection fraction, and for the whole group the mean ejection fraction increased from 63 (5) \% at rest to $67(6) \%$ at peak exercise $(p<0.001)$.

Before angioplasty 64 patients had stress induced regional abnormalities of wall motion. After the procedure these tended to disappear in association with the overall improvement in left ventricular function. In patients with continuing stress related left ventricular decompensation, however, regional abnormalities of wall motion usually persisted. In seven of the nine patients who showed delayed recovery of left ventricular function the disappearance of regional abnormalities was also delayed.

GROUP 2 ( $>20 \%$ RESIDUAL STENOSIS)

Coronary angioplasty produced complete symptomatic relief in all eight patients and an increase in peak workload during bicycle ergometry from 616 (251) to 740 (363) W.min ( $p=N S$ ).

Before angioplasty thallium-201 scintigraphy during exercise showed reversible myocardial perfusion defects in every patient, but after the procedure the defects disappeared in six patients. Despite the improvement in myocardial perfusion, radionuclide ventriculography remained persistently abnormal three to six months after coronary angioplasty with stress induced increase in ventricular volume associated with reductions in ejection fraction (65 (6) \% at rest to $56(5) \%$ during stress, p $<0.01)$. Seven of the patients showed persistent regional abnormalities of wall motion.

\section{Discussion}

The findings in this study show that successful $\vec{c}$ coronary angioplasty with a residual stenosis $<50 \% \stackrel{+}{\rightarrow}$ of the luminal diameter of the coronary artery gives early relief of angina in most patients. The $\frac{\bar{c}}{\mathrm{c}}$. improvement in symptoms was associated with $a_{\widetilde{\sigma}}$ restoration of regional myocardial perfusion as asses- $\Omega$ sed by thallium-201 perfusion scintigraphy. Nevertheless subclinical stress induced left ventricular $\overrightarrow{0}$ dysfunction during gated radionuclide ven- $-\overrightarrow{-}$ triculography often persisted unless the coronary $\vec{\sigma}$ artery was widely patent with a residual stenosis of $\leqslant 20 \%$. In some patients with wide coronary patency, however, left ventricular function was not? fully recovered for up to three months. This suggests $i \omega$ that restoration of normal perfusion is sometimes delayed until healing at the angioplasty site is com- 0 plete.

The efficacy of coronary angioplasty for treatment $\vec{z}$ of angina is well established..$^{1-3}$ In the present series more than $90 \%$ of the patients obtained early relief of $\stackrel{3}{-}$ symptoms. Despite the clinical efficacy of coronary $\vec{\bullet}$ angioplasty, beneficial effects on left ventricularo function are more difficult to demonstrate-par-ticularly in patients with multivessel disease. ${ }^{1}$ All theo patients in the present study, however, had single vessel coronary artery disease with well preserved lefto ventricular function before angioplasty. None hado akinetic myocardial segments visible on the left $\cong$ ventricular contrast angiogram. These patients, $\overrightarrow{\overrightarrow{0}}$ therefore, were an appropriate group in which to 3 evaluate the effects of coronary angioplasty on

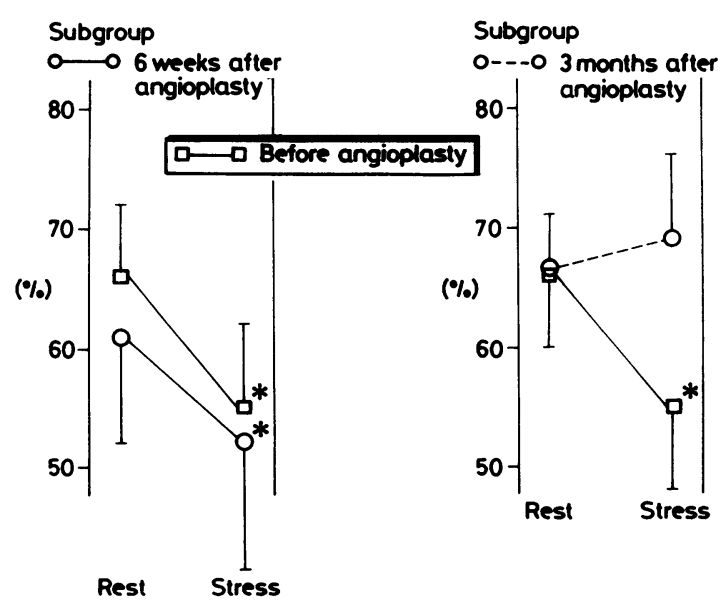

Fig 4 Left ventricular ejection fraction at rest and in response to stress before angioplasty and at 1-6 weeks and 36 months after angioplasty in nine group 1 patients with delayed recovery. ${ }^{\star} p<0.01$ compared with resting values. 
regional myocardial ischaemia and left ventricular function.

Our finding of early correction of defects in the perfusion of thallium-201 after successful coronary angioplasty must indicate a substantial improvement in regional myocardial perfusion, which accords with the findings of other investigators. ${ }^{1}$ Thus a total of 75 patients $(87 \%)$ had a normal perfusion scintigram after coronary angioplasty. Despite the improvement in myocardial perfusion, radionuclide left ventriculography showed persistent exercise induced regional abnormalities of wall motion in $33 \%$ of patients investigated within six weeks and in $19 \%$ of patients at three to six months. The response of the ejection fraction to stress was abnormal in a similar proportion of patients. This discordance between the results of radionuclide perfusion imaging and left ventriculography was also noted by the investigators of the National Heart, Lung and Blood Institute. ${ }^{1}$ Because radionuclide ventriculography has been shown by other investigators to be the more sensitive technique for the diagnosis of coronary artery disease ${ }^{45}$ the discordant findings in the present study are best explained by continuing subclinical myocardial ischaemia in the territory supplied by the dilated artery.

Not surprisingly the severity of the residual coronary stenosis after coronary angioplasty was a major determinant of continuing left ventricular dysfunction during follow up. Thus patients with a residual stenosis of $\leqslant 20 \%$ (group 1) showed restoration of normal left ventricular function in most cases. Indeed, in only $14 \%$ of patients tested did ejection fraction fail to increase with stress. All the patients with a residual stenosis of 21 to $50 \%$ (group 2), on the other hand, continued to show left ventricular decompensation despite amelioration of symptoms. Clearly, therefore, in patients recovering from coronary angioplasty a residual stenosis of $21-50 \%$, while fulfilling conventional criteria for angiographic success, does not ensure complete correction of the left ventricular response to exercise. Indeed early after angioplasty continuing left ventricular dysfunction may remain detectable by radionuclide ventriculography in patients with a residual stenosis of $<20 \%$. We identified nine patients of this type and all of them showed exercise induced reductions in left ventricular ejection fraction six weeks after angioplasty. Importantly, however, contractile function had recovered at six months in every case.

These observations indicate that after coronary angioplasty a residual stenosis of $<50 \%$ may continue to cause important (albeit subclinical) obstruction to coronary flow. This is in marked contrast with the usual experience in coronary artery disease when stenoses of $<50 \%$ are usually of no functional significance. ${ }^{6}$ The explanation for this apparent paradox may lie in the mechanism of coronary angioplasty, which causes plaque rupture, intimal dissection, and adventitial stretching with or without local aneurysm formation. ${ }^{78}$ Thus despite dilatation of the diseased arterial segment the dynamics of coronary flow will remain significantly disturbed by the damage to the vessel wall. It is reasonable to assume, however, that healing and endothelialisation of the lesion will improve coronary flow, and this may account for the late recovery of left ventricular function seen in some group 1 patients with a residual stenosis of $<20 \%$.

Thus coronary angioplasty with a residual stenosis $\leqslant 20 \%$ improves both myocardial perfusion and left ventricular function. Nevertheless, the improvement in left ventricular function may be delayed for up to three months until arterial healing at the angioplasty site is complete. When the residual stenosis is between 21 and $50 \%$ subclinical exercise induced left ventricular decompensation may persist.

\section{References}

1 Rosing DR, Van Raden MJ, Mincemoyer RM, et al. Exercise, electrocardiographic and functional responses after percutaneous transluminal coronary angioplasty. Am J Cardiol 1984;53:36c-41c.

2 Kent KM, Bonow RO, Rosing DR, et al. Improved myocardial function during exercise after successful percutaneous transluminal coronary angioplasty. $N$ Engl J Med 1982;306:441-6.

3 Sowton E, Timmis AD, Crick JCP, Griffin B, Yates AK, Deverall P. Early results after percutaneous transluminal coronary angioplasty in 400 patients. $\mathrm{Br}$ Heart $J$ 1986;56:115-20.

4 Johnstone DE, Sands JM, Berger HJ, et al. Comparison of exercise radionuclide angiocardiography and thallium-201 myocardial perfusion imaging in coronary artery disease. Am J Cardiol 1980;45:1113-9.

5 Caldwell J, Hamilton GV, Sorensen SJ, Ritchie JL, Williams DL, Kennedy JW. The detection of coronary artery disease with radonuclide techniques: a comparison of rest-exercise thallium imaging and ejection fraction response. Circulation 1980;61:610-9.

6 Lance Gould K, Schelbert HR, Phelps ME, Hoffman EJ. Noninvasive assessment of coronary artery stenoses with myocardial perfusion imaging during pharmacologic coronary vasodilatation. Am J Cardiol 1979;43:200-8.

7 Block PC, Myler RK, Stertzer S, Fallon JT. Morphology after transluminal angioplasty in human beings. N Engl J Med 1981;305:382-5.

8 Sanburn TA, Faxon DP, Haudenschild C, Gottsman SB, Ryan TJ. The mechanism of angioplasty: evidence for aneurysm formation in experimental atherosclerosis. Circulation 1983;68:1136-40. 